\title{
Technologies and new approaches used by the INGV EMERGEO Working Group for real-time data sourcing and processing during the Emilia Romagna (northern Italy) 2012 earthquake sequence
}

\author{
EMERGEO Working Group: \\ Giuliana Alessio ${ }^{1}$, Laura Alfonsi ${ }^{2}$, Carlo Alberto Brunori ${ }^{3}$, Pierfrancesco Burrato ${ }^{4}$, Giuseppe Casula ${ }^{5}$, \\ Francesca Romana Cinti ${ }^{4}$, Riccardo Civico ${ }^{4}$, Laura Colini ${ }^{3}$, Luigi Cucci ${ }^{4}$, Paolo Marco De Martini ${ }^{4}$, \\ Paola Montone ${ }^{4}$, Marco Moro ${ }^{3}$, Rosa Nappi ${ }^{1}$, Anna Nardi ${ }^{3}$, Rosa Nave ${ }^{1}$, Daniela Pantosti ${ }^{4}$, \\ Antonio Patera ${ }^{4}$, Arianna Pesci ${ }^{5}$, Maurizio Pignone ${ }^{3}$, Stefania Pinzi ${ }^{4}$, Stefano Pucci ${ }^{4}$, \\ Paola Vannoli ${ }^{4}$, Alessandra Venuti ${ }^{2}$, Fabio Villani ${ }^{4}$

\footnotetext{
${ }^{1}$ Istituto Nazionale di Geofisica e Vulcanologia, Sezione di Napoli, Osservatorio Vesuviano, Napoli, Italy

2 Istituto Nazionale di Geofisica e Vulcanologia, Sezione Roma 2, Roma, Italy

${ }^{3}$ Istituto Nazionale di Geofisica e Vulcanologia, Centro Nazionale Terremoti, Roma, Italy

${ }^{4}$ Istituto Nazionale di Geofisica e Vulcanologia, Sezione Roma 1, Roma, Italy

${ }^{5}$ Istituto Nazionale di Geofisica e Vulcanologia, Sezione di Bologna, Bologna, Italy
} Emanuela Falcucci ${ }^{4}$, Fabrizio Galadini ${ }^{4}$, Germana Gaudiosi ${ }^{1}$, Stefano Gori ${ }^{4}$, Maria Teresa Mariucci ${ }^{4}$,

\section{Article history}

Received July 19, 2012; accepted August 10, 2012.

Subject classification:

Earthquake geology and paleoseismology, Coseismic effects, Liquefaction, GIS, Po Plain.

\section{Introduction}

On May 20, 2012, a $\mathrm{M}_{\mathrm{L}} 5.9$ seismic event hit the Emilia Po Plain, triggering intense earthquake activity along a broad area of the Po Plain across the provinces of Modena, Ferrara, Rovigo and Mantova (Figure 1). Nine days later, on May 29, 2012, a $M_{L} 5.8$ event occurred roughly $10 \mathrm{~km}$ to the $S W$ of the first main shock. These events caused widespread damage and resulted in 26 victims. The aftershock area extended over more than $50 \mathrm{~km}$ and was elongated in the WNW-ESE direction, and it included five major aftershocks with $5.1 \leq \mathrm{M}_{\mathrm{L}} \leq 5.3$, and more than 2000 minor events (Figure 1).

In general, the seismic sequence was confined to the upper $10 \mathrm{~km}$ of the crust. Minor seismicity with depths ranging from $10 \mathrm{~km}$ to $30 \mathrm{~km}$ extended towards the southern sector of the epicentral area (ISIDe, http: / / iside.rm.ingv.it/).

The thrust faulting focal mechanisms of the main shocks and the strongest aftershocks show fault planes with E-W, ENE-WSW, and WNW-ESE orientations [Pondrelli et al. 2012, Scognamiglio et al. 2012, this volume], compatible with the approximately N-S direction of the compression in the area [Montone et al. 2012].

The extensive seismic reflection data used for oil exploration [Pieri and Groppi 1981, Picotti and Pazzaglia 2008, Fantoni and Franciosi 2010] allowed the reconstruction of the main tectonic elements of the area. The active Apennine thrust fronts that are buried under the Po Plain Plio-Quaternary sediments locally consist of three N-verging arcs [Ferrarese et al. 1998, Benedetti et al. 2000, Castiglioni and Pellegrini 2001]. The most external structures, the active Ferrara and Mirandola thrusts and folds [Bigi et al. 1992], were responsible for the Emilia Romagna 2012 earthquake sequence [Bignami et al. 2012, Salvi et al. 2012, this volume].

Historical and instrumental earthquakes [e.g. Boschi et al. 2000, Rovida et al. 2011], drainage anomalies controlled by buried anticlines, active compression, and a shortening rate of ca. $<1 \mathrm{~mm} / \mathrm{a}$ [Toscani et al. 2009] testify to the Quaternary thrusts activity [DISS Working Group 2010]. In detail, the recent activity of the Ferrara and Mirandola thrusts [DISS Working Group 2010] has been responsible for drainage diversions of the Po, Secchia, Panaro and Reno rivers [Burrato et al. 2003, Burrato et al. 2012, this volume].

Just after the May 20, 2012, seismic event, the EMERGEO Working Group was active in surveying the epicentral area in the search for coseismic geological effects. The work in the field was organized according to EMERGEO procedures (http: / / emergeo.ingv.it/it/2012-06-11-07-35-01/887protocollo-operativo.html/), and it lasted for one month, with about 30 researchers and technicians of the Istituto 


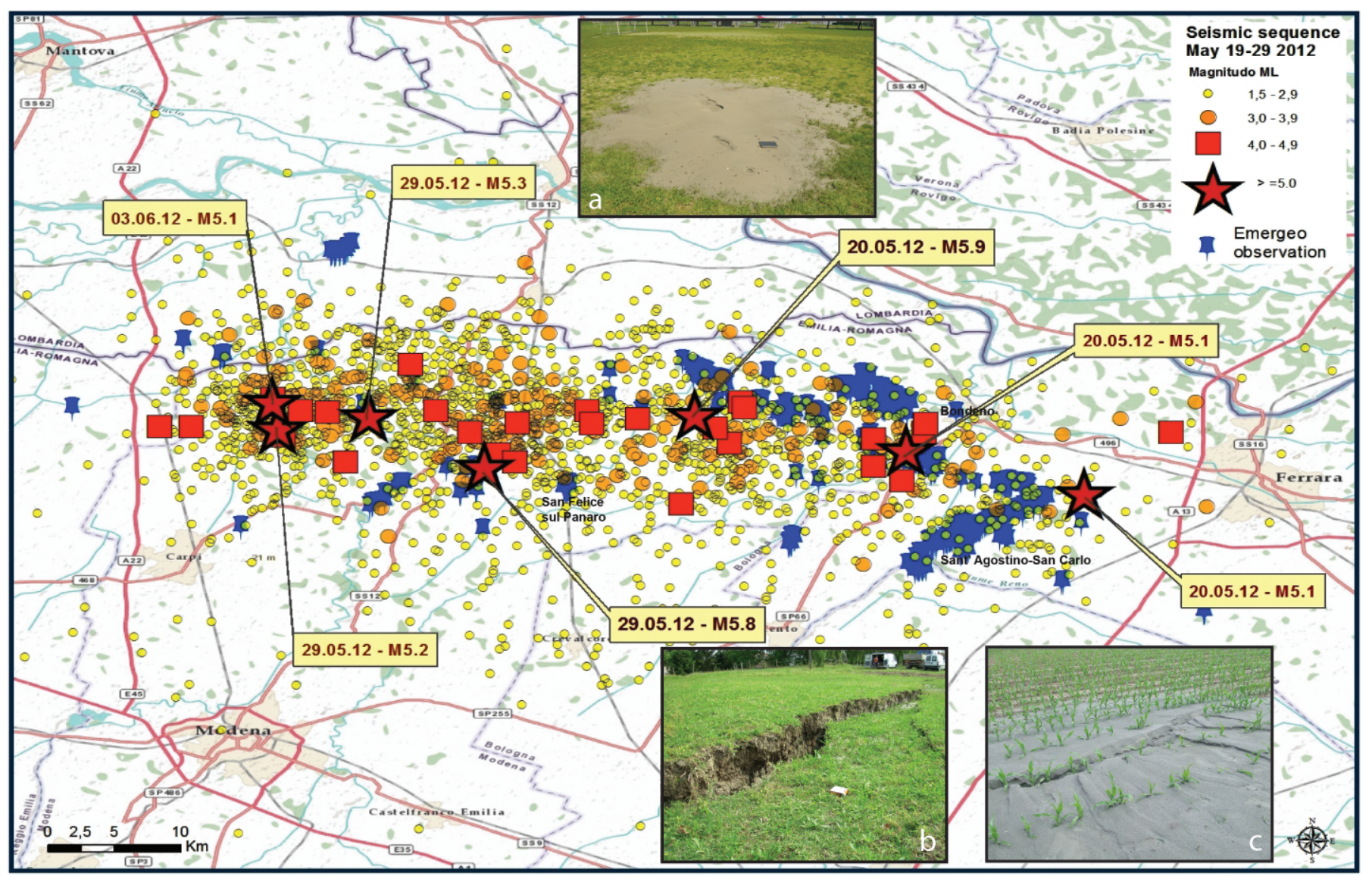

Figure 1. Seismic sequence in the Emilia Po Plain from May 19 to June 19, 2012 (ISIDe, http:/ /iside.rm.ingv.it/). In a month, more than 2000 seismic events occurred, seven with $\mathrm{M}_{\mathrm{L}} \geq 5.0$ (red stars). Blue pinpoints, observation records made by the EMERGEO Working Group. Insets: Photographs of the coseismic geological effects: (a) coalescent cones; (b) fracture; (c) liquefaction associated with fracture.

Nazionale di Geofisica e Vulcanologia (INGV; National Institute of Geophysics and Volcanology) involved alternatively in the survey. At the same time, a laboratory working group gathered, organized and interpreted the records, processing them through the EMERGEO Information System (siE) based on a GIS environment. Ground and aerial surveys were coupled with crowdsourcing data initiatives, such as the internet, social networks, and information from residents.

The most common coseismic effects surveyed by the EMERGEO teams were: 1) liquefactions related to overpressure of aquifers in buried and confined sand layers (e.g. San Felice sul Panaro, San Carlo, Sant'Agostino, and Bondeno), which occurred through several aligned vents that formed coalescent flat cones (Figure 1a); 2) extensional fractures with small vertical throws, apparently organized in an en-echelon pattern, which were observed mainly in the eastern sector and in the central area (Figure 1b); 3) liquefactions directly associable to fractures (e.g. Bondeno and San Carlo) where huge amounts of fine sand were ejected from fractures that were tens of meters long (Figure 1c). Most of these coseismic effects were also reported by other authors [e.g. Bertolini and Fioroni 2012, Di Manna et al. 2012, this volume].

The innovative tools that were employed for data gathering, processing and delivery during the EMERGEO survey included: development of the EMERGEO Information Sys- tem (siE), which turns unprocessed data into useful information; setting up of a webGIS; use of social networks for information and data delivery; and experimental data-sourcing from the internet and from residents, which accompanied the traditional survey methods (field and aerial surveys). The whole architecture allowed the collection and processing of about 2400 observation points in less than one month. The detailed analyses of this dataset will be presented in another paper [EMERGEO Working Group, submitted].

\section{Data: acquisition and methods}

Through different approaches, the EMERGEO teams collected geological coseismic surface effects: (i) field and aerial surveys; (ii) crowdsourcing from the internet and personal communications (subsequently validated by field surveys).

In all, 2156 observations were gathered from field and aerial surveys alone (helicopter flights on May 23 and 30, 2012, which were kindly made possible by the Corpo Forestale dello Stato, and a powered hang-glider trike flight on June 8, 2012). Sixty-three percent of the total data provided reliable records concerning geologic coseismic surface effects. The data were then stored in a geodatabase and analyzed using geographical information system (GIS) tools.

Field surveys were mainly aimed at the definition of the typologies and structural and morphological significance of 
the observed phenomena. The locations of the geological observations and photographs were registered using a predefined form, and stored directly as georeferenced data. Smartphones that allowed the collection and storage of field data in real-time were used also for rapid data-sharing among field teams. Through only the field surveys, 402 observations were gathered, analyzed and stored in a week, and a total of 662 data points were reported in a month (Figure 2a).

Aerial surveys were effective in integrating the dataset collected in the field, by taking approximately 1500 georeferenced photographs and recording more than $3 \mathrm{~h}$ of video. The low-altitude flights ( $200-300 \mathrm{~m}$ above ground level) allowed the whole area struck by the seismic sequence to be investigated, supported the field survey planning, and led to the identification of further features. This dataset was analyzed and processed, and the features shown in each image were characterized and positioned on the GIS. These results were available two or three days after each flight, and they were particularly useful for this specific seismic sequence that affected a vast plain area where there are very few good sites for panoramic views over large fields (Figure 2a).

For the first time, we used internet-based data sourcing, and nine days after the main shock the experimental procedure was active, to receive information from people on the geological earthquake effects. An internet form was specifically designed to gather information on surface effects that were directly associated to the earthquake (available at: http:/ / www.haisentitoilterremoto.it/emergeo.html). The form provided a simplified list of possible geological features to be flagged and editable fields for other relevant information. A specific part of the form is related to the information that is useful to locate the phenomena (i.e. street, city, and/or geographical coordinates). The entire system is based on an open-source relational database management system, and it can be queried through a graphic interface. The most reliable information was selected and transmitted daily to the field teams in the epicentral area, for verification. The response was remarkable (more than 200 completed forms), testifying to the curiosity towards an internet-based poll system (Figure 2a). Information received directly from residents constituted another important element concurring to the data-flow implementation. Communication between the EMERGEO teams and the people was particularly intense and useful during the days of the field surveys (Figure 2a).

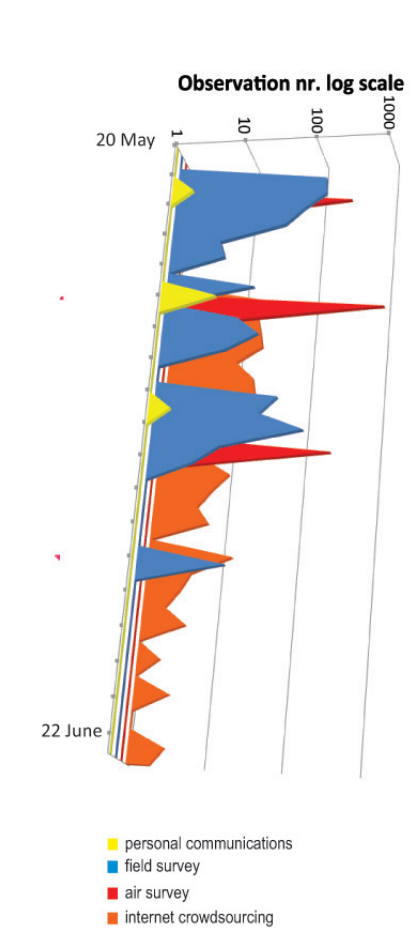

a)

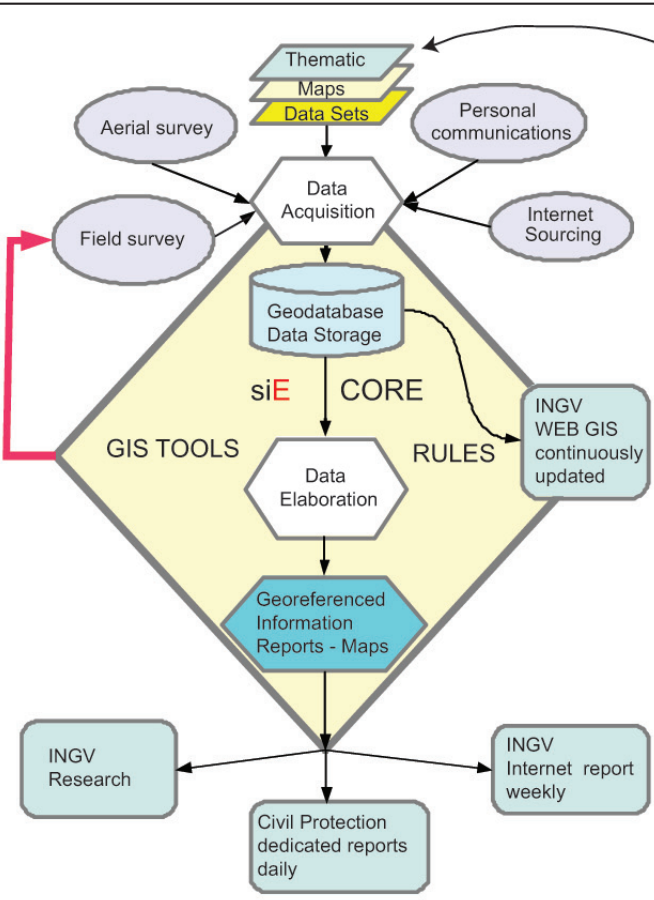

b)

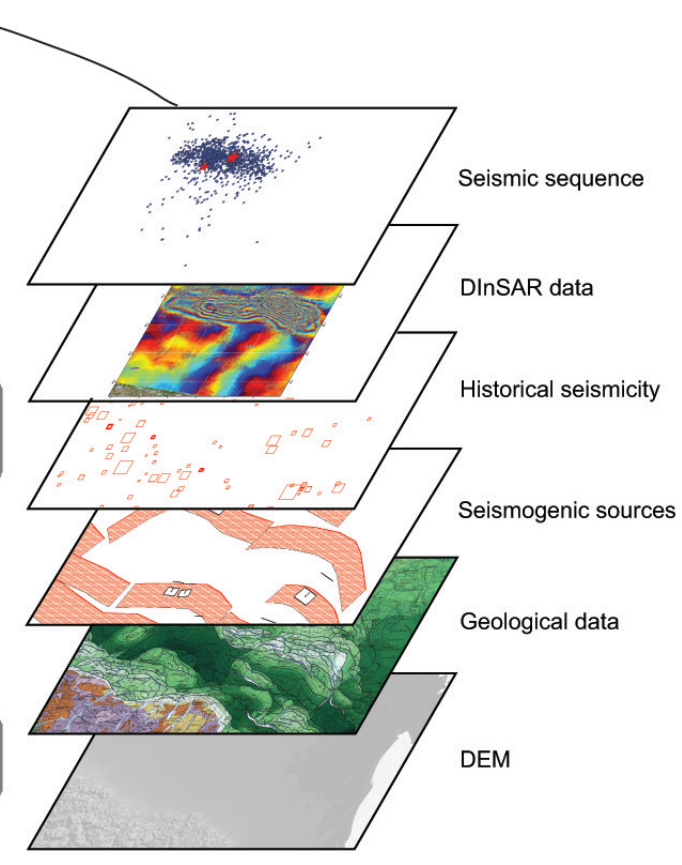

c)

Figure 2. (a) Information flow from the different investigation tools used (i.e., number of observations, log scale, vs. time). The time scale starts on May 20, 2012, the day of the main shock of the Emilia 2012 sequence $\left(M_{L}=5.9\right)$. (b) The EMERGEO Information System (siE): chart illustrating the data flux and procedures adopted for data analysis, storage and output. (c) The input data are constructed as sets of layers, each of which contains information on one type of data. In detail, the layers shown include information on: 1) the seismic sequence (ISIDe, http://iside.rm.ingv.it/); 2) the DInSAR data (http:/ / ingvterremoti.wordpress.com/2012/06/07/terremoto-in-pianura-padana-emiliana-spostamento-del-suolo-dovuto-al-terremoto-del-29052012visto-dal-satellite-italiano-cosmo-skymed/); 3) the historical seismicity [Rovida et al. 2011]; 4) the seismogenic sources [DISS Working Group 2010]; 5) the geological data [Bigi et al. 1992]; 6) the digital elevation model. 


\section{EMERGEO Information System (siE)}

The geodatabase, the procedures, the GIS tools, and the people represent the core of the EMERGEO Information System (Figure 2b). The system acts by transforming unprocessed data into information that is ready to use for the emergency management, and it leads to the production of preliminary and final reports and maps [Burrough 1986, Maguire 1991, Brunori et al. 2007]. The input data in the siE are grouped into two main categories: (i) existing base maps (e.g., geographic, geological data; DEM) and other available datasets (e.g., INGV Kharita - Geoserver portal Project; CSI 1.1 - Castello et al. [2006]; Bollettino Sismico Italiano; Italian Seismic Instrumental and Parametric Database - ISIDe; CPTI11 Rovida et al. [2011]; DISS Working Group [2010]); (ii) geological coseismic surface effects collected during the post-earthquake survey by the EMERGEO teams. The whole dataset is organized into georeferenced (latitude/longitude WGS84) multilayer information in the GIS environment (Figure 2c).

The acquired data flowed into a webGIS that was specifically created for the dissemination of original geo-information (Figure 2b). During the emergency phase, the siE system was necessary both for fixing the knowledge of the phenomena and its temporal and spatial evolution, and for planning the field surveys and the fly-overs in progress (Figure $2 \mathrm{~b}$ ).

The whole siE structure acts as a dynamic system, which filters the data through the procedures into the database and which sends back real-time information to the field operators. All of the process was constantly implemented during the emergency.

\section{Data dissemination}

During the Emilia 2012 seismic emergency, two experimental procedures were used to perform the data dissemination devoted to different target groups (general public, researchers, emergency operators, policy makers). The main instrument was set up by implementing an existing platform for image and data sharing [Pignone and Moschillo 2011, Pignone et al. 2012], and it was constituted by a webGIS application that was developed on the ESRI ArcGIS online platform (http://www.arcgis.com/). This system allowed a complete parallel representation of the information gathered by the EMERGEO Working Group and the principal databases used (Figure 2c). It provided access to geographic content shared and registered by ESRI and GIS users around the world (http://www.esriitalia.it/emergeo/). For the first time, all of the EMERGEO data collected and processed by

\section{EMERCI:O Sequenza pianura padana emiliana esri Italia}

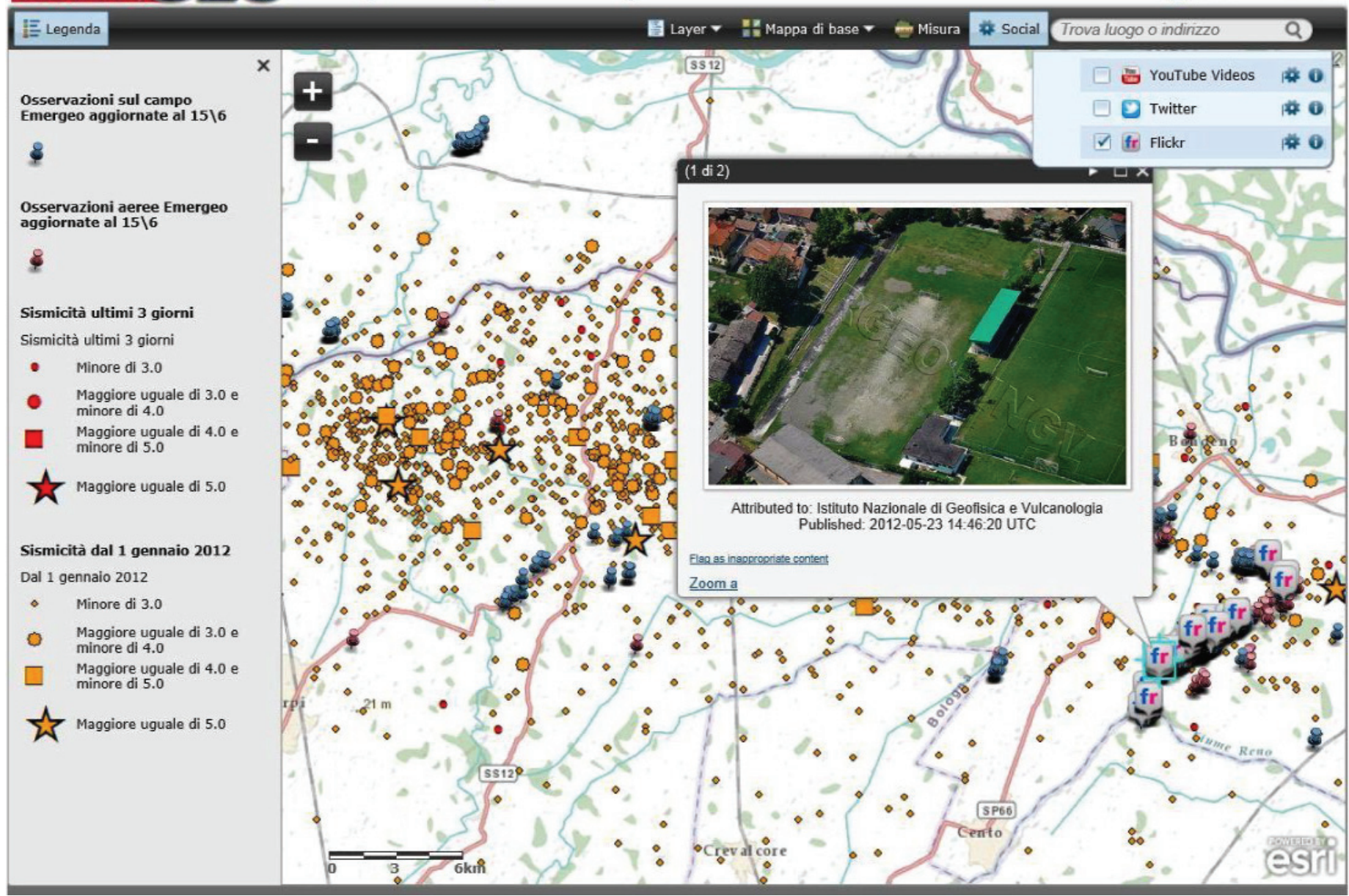

Figure 3. Screen shot depicting a typical layer of the webGIS interface and the related information that is accessible at http://www.esriitalia.it/emergeo/. 


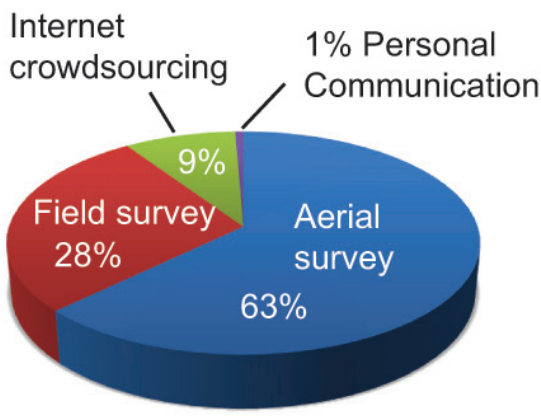

a) Raw data

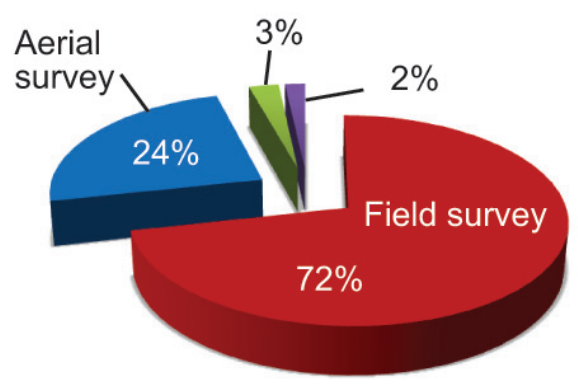

d) Fractures

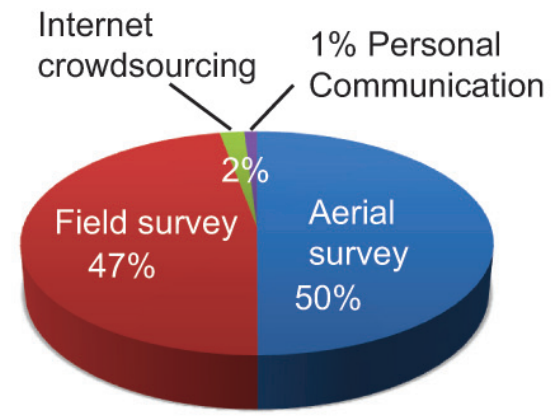

b) Analysed data

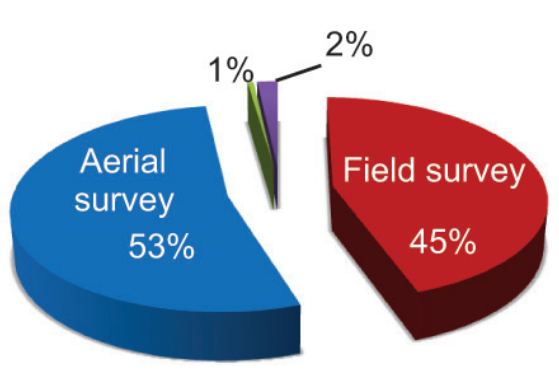

e) Liquefactions

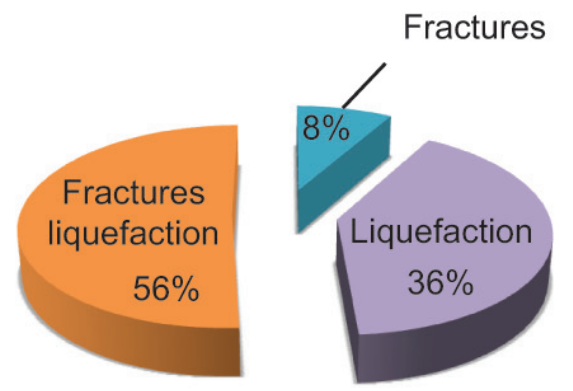

c) Total resolved features

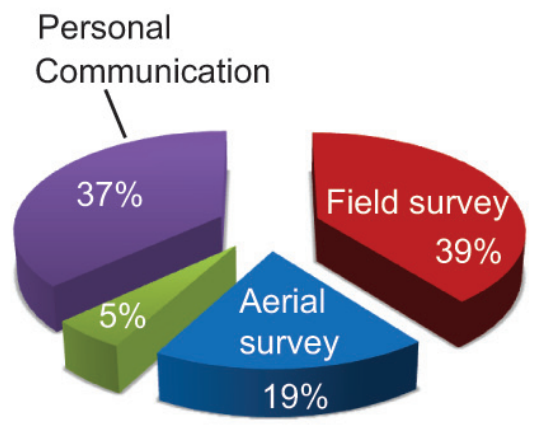

f) Weighted effectiveness

Figure 4. Schematic representations of: (a) percentages of raw data derived from the different investigating tools; (b) percentages of effective data produced by each investigating tool; (c) partitioning of the total data into specific surveyed coseismic effects; (d, e) contribution of each specific investigating tool towards surveying fractures and liquefaction phenomena; (f) representation of the weighted effectiveness of each single investigating tool once each group of data is normalised with respect to the specific effectiveness (i.e., the amount of robust data versus the total amount of data).

the $\mathrm{siE}$ were immediately available to potential users through an external interface (Figure 2c, Figure 3).

A further procedure was set up within the framework of the "Flickr" social network, as a dedicated EMERGEO space, for the diffusion of photographs of the geological effects of the earthquake. Georeferenced pictures from field and aerial surveys were detailed with full descriptions of the phenomena. These free-access images are available at http: / / www. flickr.com/photos/emergeo_ingv/ and they represent a valid communication tool between the EMERGEO researchers and the generic public (Figure 3).

\section{Discussion}

The totality of observations collected provides a dataset of about 2400 points (i.e., field and aerial surveys, personal communications, and internet data sourcing). Fifty-nine percent of this dataset has been merged into reliable information, which is useful for other researches. Figures $4 a, b$ illustrate the weight of each information source: as expected, field-based and aerial-based surveys are the most reliable information sources. Fractures associated to liquefaction and single liquefaction phenomena constitute the majority of the data, while fractures without sand emission are less represented (Figure 4c).

Figure 4 d,e shows the contribution of each method to the identification of specific features (e.g., fractures and liquefac- tion). Nevertheless, considering the weight of each survey tool with respect to its effectiveness, a quite different scenario arises (Figure 4f). In particular, personal communications from the residents contributed to $37 \%$ of the whole dataset, with a specific effective index (s.e.i) of $93 \%$. This index is obtained by scaling the amount of corrected information versus the amount of total information, as a percentage. As expected, field surveys still provide the most reliable and immediately usable data (39\% of the contribution to the whole dataset, with a s.e.i. of $100 \%)$. The aerial surveys represent $19 \%$ of whole data contributions, with a $47 \%$ s.e.i.. The internet crowdsourcing result is particularly interesting: indeed, in spite of the $5 \%$ contribution, this gains a s.e.i. of ca. $13 \%$. In conclusion, the internet and general public information data sourcing are promising tools that need further development through dedicated projects that involve specific data dissemination efforts.

\section{Conclusions}

- Field and aerial surveys produced a wide dataset of information, which allowed the reconstruction of the coseismic effects that characterized the Emilia 2012 sequence.

- A self-consistent system for data gathering, processing and delivery was set up, which produced the transformation of the unprocessed data into information that was ready to use for emergency management, research and data diffusion (siE). 
- For this seismic sequence, the EMERGEO Working Group dedicated efforts towards the development of alternative methods for collecting information through citizen engagement. Although experimental, this data coupling provided encouraging results in terms of the involvement of the public, which revealed at the same time their poor knowledge of the specific earthquake phenomenon.

- Use of social networks and internet sourcing to gather valid earthquake-related information was tentative and needs future development through specific projects.

The dissemination effort can improve the interactions among geologists / seismologists and society at large, and increase the level of confidence of the population concerning the service provided to society before, during, and after a seismic crisis.

Acknowledgements. The Corpo Forestale dello Stato is acknowledged for the flights over the seismic area, ESRI Italia for the webGIS facilities, and last but not least, the residents directly affected by the seismic sequence who actively collaborated in spite of the uneasy living conditions. We are grateful to the anonymous reviewers and the Guest Editors.

\section{References}

Benedetti, L., P. Tapponier, G.C.P. King, B. Meyer and I. Manighetti (2000). Growth folding and active thrusting in the Montello region, Veneto, northern Italy, J. Geophys. Res., 105, 739-766.

Bertolini, G., and C. Fioroni (2012). Aerial inventory of surficial geological effects induced by the recent Emilia earthquake (Italy): preliminary report, Annals of Geophysics, 55 (4); doi:10.4401/ag-6113.

Bigi, G., D. Cosentino, M. Parlotto, R. Sartori and P. Scandone (1992). Structural model of Italy and gravitymap, Quaderni della Ricerca Scientifica, 114, Consiglio Nazionale delle Ricerche (CNR), Roma.

Bignami, C., P. Burrato, V. Cannelli, M. Chini, E. Falcucci, A. Ferretti, S. Gori, C. Kyriakopoulos, D. Melini, M. Moro, F. Novali, M. Saroli, S. Stramondo, G. Valensise, P. Vannoli (2012). Coseismic deformation pattern of the Emilia 2012 seismic sequence imaged by Radarsat-1 interferometry, Annals of Geophysics, 55 (4); doi:10.4401/ag-6157.

Bollettino Sismico Italiano, Istituto Nazionale di Geofisica e Vulcanologia: http: / / bollettinosismico.rm.ingv.it

Boschi, E., E. Guidoboni, G. Ferrari, D. Mariotti, G. Valensise and P. Gasperini (2000). Catalogue of strong Italian earthquakes, 461 B.C. to 1997, Annali di Geofisica, 43 (4), 609868, with database on CD-ROM.

Brunori, C.A., G. Siletto, A. Piccin, F. Berra and E. Mozzi (2007). Verso un Sistema Informativo Geologico: l'applicativo CARGeo per la banca dati Geologica della Regione Lombardia, Rendiconti della Società Geologica Italiana, Nuova Serie, 4, 91-96.

Burrato, P., F. Ciucci and G. Valensise (2003). An inventory of river anomalies in the Po Plain, northern Italy: evidence for active blind thrust faulting, Annals of Geophysics, 46 (5), 865-882.

Burrato, P., P. Vannoli, U. Fracassi, R. Basili and G. Valensise (2012). Is blind faulting truly invisible? Tectonic-controlled drainage evolution in the epicentral area of the May 2012, Emilia-Romagna earthquake sequence (northern Italy), Annals of Geophysics, 55 (4); doi:10.4401/ag-6182.

Burrough, P.A. (1986). Principles of geographical information systems for land resource assessment, Clarendon Press, Oxford, UK, 194 pp.

Castello, B., G. Selvaggi, C. Chiarabba and A. Amato (2006). CSI Catalogo della sismicità italiana 1981-2002, versione 1.1. INGV-CNT, Roma, http: / / csi.rm.ingv.it/

Castiglioni, G.B., and G.B. Pellegrini, eds. (2001). Note illustrative della Carta Geomorfologica della Pianura Padana, Geogr. Fis. Din. Quat., Suppl. IV, 207 pp.

Di Manna, P., L. Guerrieri, L. Piccardi, E. Vittori, D. Castaldini, A. Berlusconi, L. Bonadeo, V. Comerci, F. Ferrario, R. Gambillara, F. Livio, M. Lucarini and A.M. Michetti (2012). Ground effects induced by the 2012 seismic sequence in Emilia: implications for seismic hazard assessment in the Po Plain, Annals of Geophysics, 55 (4); doi:10.4401/ag-6143.

DISS Working Group (2010). Database of Individual Seismogenic Sources (DISS), Version 3.1.1: A compilation of potential sources for earthquakes larger than M 5.5 in Italy and surrounding areas; http: / / diss.rm.ingv.it/ diss / (C) INGV 2010 - Istituto Nazionale di Geofisica e Vulcanologia. All rights reserved).

EMERGEO Working Group (2012). Coseismic geological effects associated with the Emilia earthquake sequence of May-June 2012 (northern Italy), Nat. Haz. Earth Sys., submitted.

Fantoni, R., and R. Franciosi (2010). Tectono-sedimentary setting of the Po Plain and Adriatic foreland, Rend. Fis. Acc. Lincei, 21: S197-S209, doi:10.1007/s12210-010-0102-4.

Ferrarese, F., U. Sauro and C. Tonello (1998). The Montello Plateau, karst evolution of an alpine neotectonic morphostructure, Z. Geomorphol. N. F., 109, 41-62.

ISIDe Working Group (INGV, 2010). Italian Seismological Instrumental and parametric database: http: / / iside.rm. ingv.it/

Kharita-Geoserver Portal: http: / / kharita.rm.ingv.it/dmap/ Maguire, D.J. (1991). An overview and definition of GIS, In: D.J. Maguire, M.F. Goodchild and D. Rhind (eds.), Geographical Information Systems: Principles and Applications, John Wiley \& Sons, Inc., New York, 9-20.

Montone, P., M.T. Mariucci and S. Pierdominici (2012). The Italian present-day stress map, Geophys. J. Int., 189, 705716; doi:10.1111/j.1365-246X.2012.05391.x.

Picotti, V., and F.J. Pazzaglia (2008). A new active tectonic model for the construction of the northern Apennines mountain front near Bologna (Italy), J. Geophys. Res., 
113, B08412; doi:10.1029/2007JB005307.

Pieri, M., and G. Groppi (1981). Subsurface geological structure of the Po Plain, Italy, Pubbl.414, Consiglio Nazionale delle Ricerche, CNR, Agip, Progetto Finalizzato Geodinamica, Rome, 1981, 23 pp.

Pignone, M., and R. Moschillo (2011). GEOSIS: dall'Earthquake Report al webGIS, Quaderni di Geofisica, 94, ISSN: 1590-2595.

Pignone, M., R. Moschillo and R. Cogliano (2012). Geodatabase e report di sismicità, Rendiconti Online della Società Geologica Italiana, vol. 19.

Pondrelli, S., S. Salimbeni, P. Perfetti and P. Danecek (2012). Quick regional centroid moment tensor solutions for the Emilia 2012 (northern Italy) seismic sequence, Annals of Geophysics, 55 (4); doi:10.4401/ag-6146.

Rovida, A., R. Camassi, P. Gasperini and M. Stucchi, eds. (2011). CPTI11, the 2011 version of the Parametric Catalogue of Italian Earthquakes, Milano/Bologna; http: / / emidius.mi.ingv.it/CPTI11/

Salvi, S., C. Tolomei, J.P. Merryman Boncori, G. Pezzo, S. Atzori, A. Antonioli, E. Trasatti, R. Giuliani, S. Zoffoli and A. Coletta (2012). Activation of the SIGRIS monitoring system for ground deformation mapping during the Emilia 2012 seismic sequence, using COSMO-SkyMed InSAR data, Annals of Geophysics, 55 (4); doi:10.4401/ag-6181.

Scognamiglio, L., L. Margheriti, F.M. Mele, E. Tinti, A. Bono, P. De Gori, V. Lauciani, F.P. Lucente, A.G. Mandiello, C. Marcocci, S. Mazza, S. Pintore and M. Quintiliani (2012). The 2012 Pianura Padana Emiliana seimic sequence: locations, moment tensors and magnitudes, Annals of Geophysics, 55 (4); doi:10.4401/ag-6159.

Toscani, G., P. Burrato, D. Di Bucci, S. Seno and G. Valensise (2009). Plio-Quaternary tectonic evolution of the northern Apennines thrust fronts along the Bologna-Ferrara section (Po Plain, Italy), based on geological observations and analogue modelling: seismotectonic implications, Ital. J. Geosci., 128, 605-613.

\footnotetext{
${ }^{\star}$ Corresponding author: Maria Teresa Mariucci, Istituto Nazionale di Geofisica e Vulcanologia, Sezione Roma 1, Roma, Italy; email: mariateresa.mariucci@ingv.it. 